\title{
Carbon burp and transient global warming during the Paleocene-Eocene Thermal Maximum
}

\section{Appy SLUIJS}

Laboratory of Palaeobotany and Palynology, Institute of Environmental Biology, Utrecht University, Netherlands; A.Sluijs@uu.nl

The Paleocene-Eocene Thermal Maximum (PETM), 55.5 Myr ago, was a geologically brief ( $170 \mathrm{kyr}$ ) episode of globally elevated temperatures that occurred superimposed on the long-term late Paleocene and early Eocene warming trend. It was marked by a $5-8^{\circ} \mathrm{C}$ warming in both lowand high-latitude regions, a perturbation of the hydrological cycle and a major biotic response on land and in the oceans, including radiations, extinctions and migrations (see overviews in Bowen et al., 2006; Sluijs et al., 2007a). In addition, the PETM was associated with a pronounced negative carbon isotope excursion (CIE), recorded as a $>2.5 \%$ o decrease in the stable carbon isotope composition $\left(\delta^{13} \mathrm{C}\right)$ of sedimentary components (e.g., Kennett and Stott, 1991; Koch et al., 1992) (Fig. 1). The CIE can only be explained by a carbon "burp" —a massive (at least $1.5 \times 10^{18} \mathrm{~g}$; $1500 \mathrm{Gt}$ ) injection of ${ }^{13} \mathrm{C}$-depleted carbon into the ocean-atmosphere system (Dickens et al., 1995).

Recent work has focused on elucidating the source and injection mechanisms of the carbon that caused the $\mathrm{CIE}$, as well as on addressing the question of whether the ${ }^{13} \mathrm{C}$-depleted carbon caused the warming or acted as a positive feedback in an already warming world. Other questions of interest include whether the PETM was a unique event in the early Paleogene greenhouse world, and the relevance of the fossil carbon burp to the current carbon burp resulting from fossil fuel burning.

\section{Ocean acidification}

Analogous to the modern situation, the injection of a large mass of $\mathrm{CO}_{2}$ or $\mathrm{CH}_{4}$ (which would have been oxidized to $\mathrm{CO}_{2}$ within a century at most; Schmidt and Shindell, 2003) should have increased the acidity of the ocean. As a result, a shallowing of the calcite compensation depth (CCD) and dissolution of deep-sea carbonates should have occurred, thereby buffering the seawater pH change (Dickens et al., 1997). Indeed, the dissolution of deep-sea carbonates has been documented in various deep-ocean basins, based on the occurrence of clay layers as well as biogenic calcite fragmentation (e.g., Zachos et al., 2005) (Fig. 1). The severity of dissolution, however, appears to have been highly variable between various basins (Zeebe and Zachos, 2007), which is as yet unexplained.

\section{Carbon sequestration}

The distribution of deep-sea carbonate abundances also points to one mechanism of carbon sequestration. Carbonate accumulation rates at many sites appear to have been very high towards the termination of the PETM - the lysocline (the

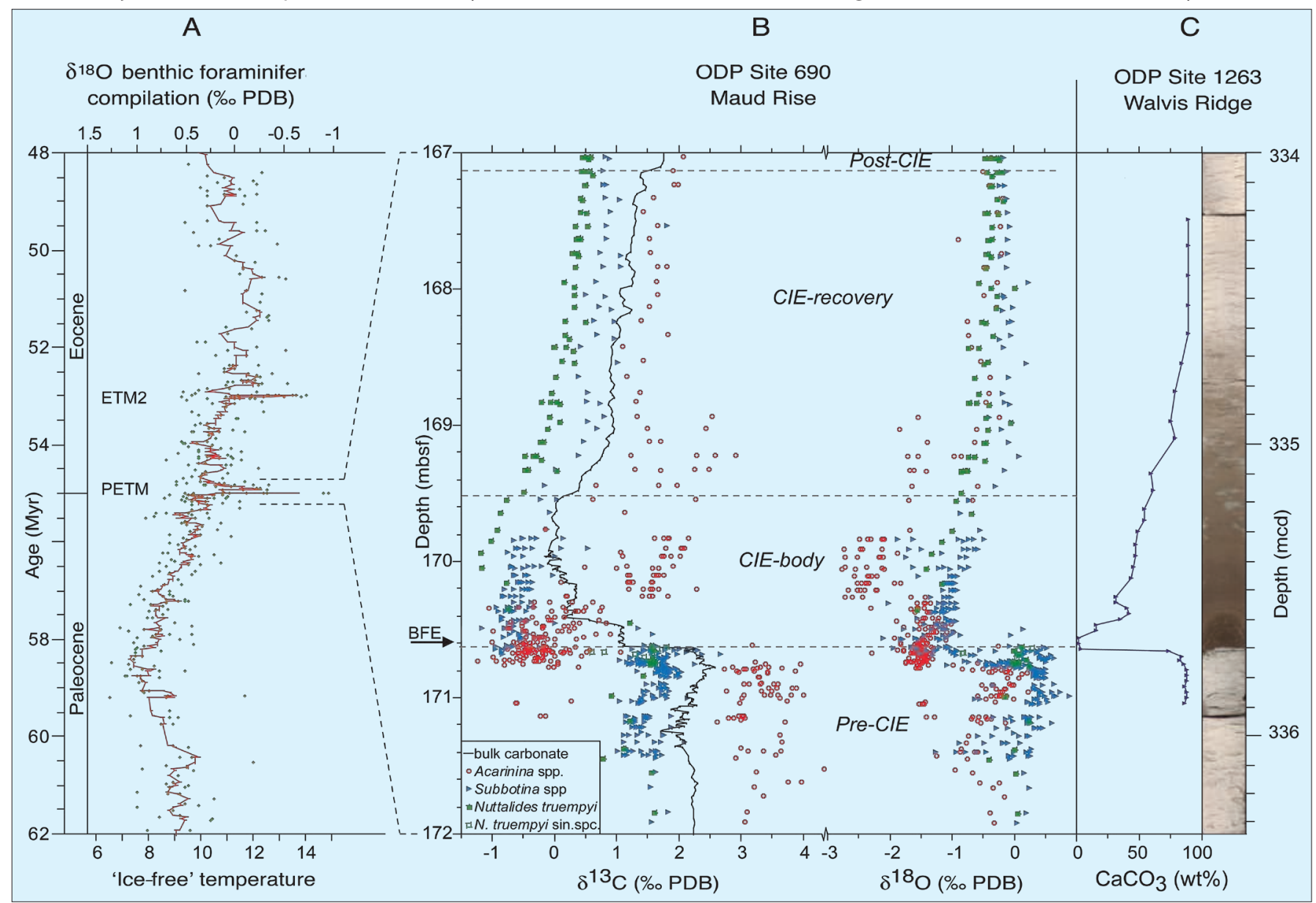

Figure 1: A) Benthic foraminifer ${ }^{18} \mathrm{O}$ record from 62-48 Myr (adapted from Zachos et al., 2001; data for ETM2 represent the Cibicidoides record from Lourens et al., 2005). $\delta^{18} \mathrm{O}$ values represent corrected values (cf.Zachos et al., 2001). An additional correction of $-0.25 \%$ was applied to the ETM2 Cibicidoides values to synchronize baseline levels between the records. ETM2 = Eocene Thermal Maximum 2 (also referred to as $\mathrm{H1}$ or Elmo), $\mathrm{PETM}=$ Paleocene-Eocene Thermal Maximum. $B$ ) Compilation of $\delta^{13} \mathrm{C}$ and $\delta^{18} \mathrm{O}$ values across the PETM of planktic foraminifers (surface dweller Acarinina and thermocline dweller Subbotina spp.; mostly single specimens), benthic foraminifer (Nuttallides truempyi) and bulk carbonate from ODP Site 690 from Maud Rise in the Weddell Sea (data compilation and figure modified from Sluijs et al., 2007a). C) Carbonate weight $\%$ record and core photo of ODP Site 1263 at Walvis Ridge, southeastern Atlantic (adapted from Zachos et al., 2005), showing dissolution and resulting clay layer. BFE refers to the main phase of benthic foraminifer extinction, mbsf = meters below sea floor; $m c d=$ meters composite depth. 


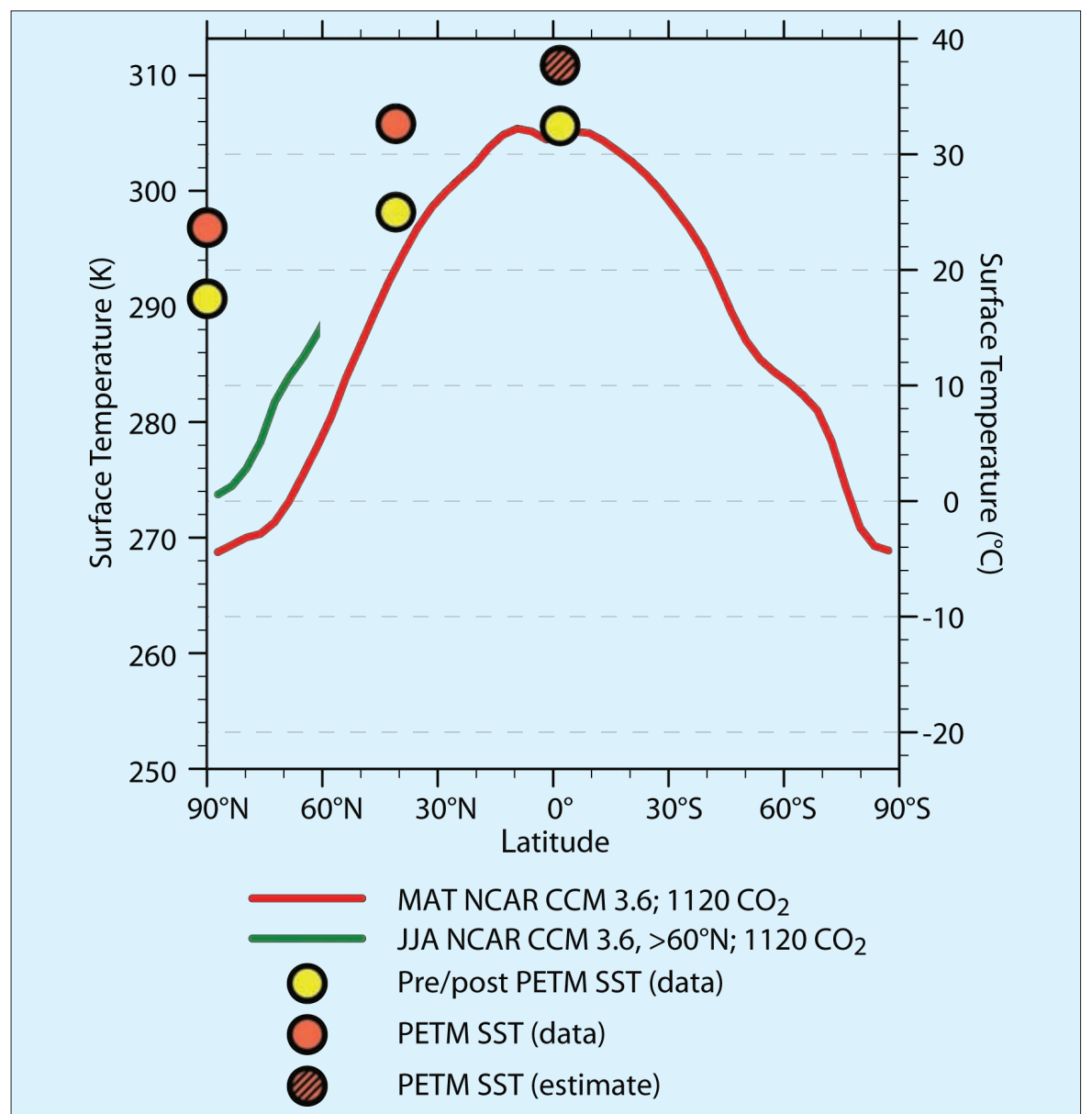

Figure 2: Data-model comparison of the late Paleocene-early Eocene and PETM meridional temperature gradient. Estimated value for PETMSSTs in the tropics is derived by adding $5^{\circ} \mathrm{C}$ tropical warming (Zachos et al., 2003) to the background temperatures of Pearson et al. (2007). Mid-latitude data from Zachos et al. (2006) and Arctic data from Sluijs et al. (2006). Model (NCAR's Community Climate System Model 3.6 with Eocene boundary conditions) output (Huber and Nof, 2006) represents mean annual temperature (MAT; red line). Arctic proxy estimates may be skewed towards summer temperature and are, therefore, compared to model predictions for June, July, August (JJA) $>60^{\circ} \mathrm{N}$ (green line; see text).

depth in the ocean below which the rate of dissolution of calcite increases dramatically) was located even deeper than prior to the PETM - resulting in sequestration of large amounts of carbon (e.g., Kelly et al., 2005; Zachos et al., 2005). This phenomenon is model-predicted (Dickens et al., 1997) and was probably driven by silicate weathering, which slowly recharged the ocean with carbonate ion and eventually led to carbonate ion over-saturation and extremely good preservation of calcite on the sea floor. In some regions, particularly the Arctic, organic carbon burial increased during the PETM due to increased river runoff, causing more organic production, as well as stratification and bottom water anoxia. Excess burial perhaps comprised in the order of $800 \mathrm{Gt}$ of carbon during the PETM in the Arctic alone (Sluijs et al., 2007b).

\section{Meridional temperature gradients}

The application of the organic paleothermometer $\mathrm{TEX}_{86^{\prime}}$ as well as oxygen isotope data (Fig. 1) on well-preserved foraminifers, has recently led to a much better quantification of sea surface temperatures (SSTs) across the PETM. Background late
Paleocene and early Eocene were already warm, with SSTs of $\sim 32^{\circ} \mathrm{C}$ in the tropics (Pearson et al., 2007) and $25^{\circ} \mathrm{C}$ and $17^{\circ} \mathrm{C}$ for mid- and high-latitude oceans, respectively (e.g., Sluijs et al., 2006; Zachos et al., 2006). During the PETM, tropical as well as mid-latitude and Arctic SSTs rose by $5-8^{\circ} \mathrm{C}$ (Zachos et al., 2003, 2006; Sluijs et al., 2006) (Fig. 2). Such temperatures in the high Arctic are supported by biogeographical data, such as the abundant occurrence of subtropical dinoflagellates (Sluijs et al., 2006), and other geochemical information (see e.g., Weijers et al., 2007). Hence, the meridional temperature gradient was only $15^{\circ} \mathrm{C}$ during both background and PETM conditions, although it remains unclear if the Arctic data represent mean annual or summer temperatures (Sluijs et al., 2006, 2007b). Yet, even if they represent summer temperatures, current generation fully coupled climate models cannot simulate such reduced gradients, even when the model is fed with Eocene geography and high $\mathrm{CO}_{2}$ concentrations (Huber and Nof, 2006) (Fig. 2). This suggests that higherthan-modern greenhouse gas concentrations must have operated in conjunction with feedback mechanisms that either amplified polar temperatures or cooled the tropics, and that are not incorporated in the models (Sluijs et al., 2006). Potential mechanisms for polar warming and tropical cooling include polar stratospheric clouds (Sloan and Pollard, 1998) and hurricane-induced ocean mixing (Emanuel et al., 2004; Sriver and Huber, 2007), respectively.

Interestingly, the meridional temperature gradient did not further decrease during the PETM. This can be partly explained by the absence of ice-albedo feedbacks, since the Arctic was already ice free prior to the PETM. Additionally, it implies that the mechanism that caused the reduced meridional temperature gradient did not become amplified during the PETM (Sluijs et al., 2006).

\section{Additional early Eocene hyperthermals}

Recent work shows that a phase similar to the PETM occurred at $53.5 \mathrm{Myr}$ (Lourens et al., 2005) (referred to in the literature as $\mathrm{H}-1$, Elmo or Eocene Thermal Maximum 2 (ETM2)), and possible additional related phases at $53.1 \mathrm{Myr}(\mathrm{I}-1)$ and $~ 52.3 \mathrm{Myr}(\mathrm{K}$ or X) (Cramer et al., 2003; Röhl et al., 2005; Nicolo et al., 2007). Although documentation of these phases is, as yet, relatively incomplete, the available information indicates that these additional hyperthermals were also associated with massive injection of ${ }^{13} \mathrm{C}$-depleted carbon, ocean acidification and perturbations of the hydrological cycle, though less pronounced than during the PETM. Orbital tuning of the complete late Paleocene and early Eocene record at Walvis Ridge (South Atlantic) has indicated a link between the timing of the hyperthermals and eccentricity maxima (Lourens et al., 2005; Westerhold et al., 2007), which would have implications for the mechanisms that caused global change during the hyperthermals.

\section{Leads and lags and mechanisms of carbon input}

One prominent example of biotic change associated with the onset of the CIE is recorded along continental margins, where sediment sequences from all latitudes contain high abundances of dinoflagellate cysts belonging to the subtropical genus Apectodinium (Crouch et al., 2001; Sluijs et al., 2007a). In part, this must be associated with the PETM warming. However, in stratigraphically expanded marginal marine sections from the New Jersey Shelf and the North Sea, as well as in a section from New Zealand, the onset of the Apectodinium acme started some $5 \mathrm{kyr}$ prior to the CIE (Sluijs et al., 2007b). Additionally, the onset of the PETM SST warming 
at New Jersey led the CIE by several thousands of years (but lagged the onset of the Apectodinium acme) (Sluijs et al., 2007b). This indicates that warm SST was not the only environmental control on Apectodinium abundances. Moreover, it suggests that the carbon burp that caused the CIE was a result of initial climate change and acted as a positive feedback. This scenario fits the model that $\mathrm{CH}_{4}$ release from submarine hydrates caused the CIE (Dickens et al., 1995). If this pre-CIE warming was global, it was likely induced by greenhouse forcing, suggesting that the PETM warming and ocean acidification were caused by at least two sources of carbon (Sluijs et al., 2007b).

\section{Concluding remarks}

The past years of research on the PETM and the more recently discovered additional hyperthermals have resulted in a clearer picture of these critical phases in Earth's history. Improved drilling techniques (Integrated Ocean Drilling Program) have resulted in the recovery of complete sections, and new analytical techniques have contributed to much better quantitative estimates of SSTs. Moreover, high-resolution studies on expanded marginal marine sequences have identified leads and lags in the interaction between the climate system and the carbon cycle during the onset of the PETM. The new data provide fundamental constraints for modeling global climate and carbon cycling, and are increasingly leading to an improved description and understanding of the state and dynamics of a (in this case the early Paleogene) greenhouse world.

\section{Acknowledgements}

I thank the Netherlands Organisation for Scientific Research for funding (VENI grant 863.07.001) and for their continued support of the Integrated Ocean Drilling Program. I also thank all my 'hyperthermal' colleagues, amongst others Stefan Schouten, Jim Zachos, Jerry Dickens, Ursula Röhl, Lucas Lourens, Jaap Sinninghe Damsté, Gert-Jan Reichart, Matt Huber, Gabe Bowen, Mark Pagani, Ellen Thomas, Dick Kroon, Cedric John, Steven Bohaty and Henk Brinkhuis for discussions over the past years.

\section{References}

Lourens, L.J., Sluijs, A., Kroon, D., Zachos, J.C., Thomas, E., Röhl, U., Bowles, J. and Raffi, I., 2005: Astronomical pacing of late Palaeocene to early Eocene global warming events, Nature, 435(7045): 1083-1087.

Sluijs, A. Schouten, S., Pagani, M., Woltering, M., Brinkjuis, H., Sinninghe Damsté, J.S., Dickens, G.R., Huber, M., Reichart, G.-J., Stein, R., Matthiessen, J., Lourens, L.J., Pedentchouk, N., Backman, J., Moran, K. and the Expedition 302 Scientists, 2006: Subtropical Arctic Ocean temperatures during the Palaeocene/Eocene thermal maximum, Nature, 441(7093): 610-613.

Sluijs, A., Bowen, G.J., Brinkhuis, H., Lourens, L.J. and Thomas, E., 2007a: The Palaeocene-Eocene thermal maximum super greenhouse: biotic and geochemical signatures, age models and mechanisms of global change. In: M. Williams, et al. (Eds), Deep time perspectives on Climate Change: Marrying the Signal from Computer Models and Biological Proxies. The Micropalaeontological Society, Special Publications, The Geological Society, London, pp. 323-349.

Sluijs, A., Brinkhuis, H., Schouten, S., Bohaty, S.M., John, C.M., Zachos, J.C., Sinninghe Damsté, J.S., Crouch, E.M. and Dickens, G.R., 2007b: Environmental precursors to rapid light carbon injection at the Paleocene/Eocene boundary, Nature, 450: 1218-1221.

Zachos, J.C. Röhl, U., Schellenberg, S.A., Sluiis, A., Hodell, D.A., Kelly, D.C., Thomas, E., Nicolo, M., Raffi, l., Lourens, L.J., McCarren, H. and Kroon, D., 2005: Rapid Acidification of the Ocean during the Paleocene-Eocene Thermal Maximum, Science, 308(5728): $1611-1615$

For full references please consult:

www.pages-igbp.org/products/newsletter/ref2008_1.htm

\section{Pleistocene records of marine carbonate chemistry}

\author{
Bärbel HönISCH ${ }^{1}$, J. Yu ${ }^{2}$ and N.G. Hemming ${ }^{3}$ \\ 'Lamont-Doherty Earth Observatory, Palisades, USA; hoenisch@ldeo.columbia.edu \\ ${ }^{2}$ Cambridge University, UK \\ ${ }^{3}$ Queens College, Flushing, USA
}

Ice core records provide the only direct archive for past atmospheric gas composition, and records spanning the past 670 kyr BP reveal a tight correlation between surface temperatures and atmospheric $\mathrm{pCO}_{2}$ (Petit et al., 1999; Siegenthaler et al., 2005). However, what determines the glacial and interglacial $\mathrm{pCO}_{2}$ extremes (i.e., 280 vs. 200 ppm), and where the $\mathrm{CO}_{2}$ was stored is poorly understood, although it is clear that the ocean is the only reservoir that could have absorbed the missing $\mathrm{CO}_{2}$ from the atmosphere (Broecker, 1982). This uncertainty hampers the prediction of future climate change with continued anthropogenic release of $\mathrm{CO}_{2}$, and there is a pressing need to better understand the interplay between atmospheric $\mathrm{pCO}_{2}$ and the much larger oceanic carbon reservoir.

There are several proxies for reconstructing marine carbonate chemistry, all of which have limitations (see Hönisch and Hall, 2007). Although the uncertainties may be large, multiproxy approaches for the late Pleistocene yield an increasingly consistent picture. Paleoreconstructions focus on two approaches: (1) To study the sensitivity of climate to greenhouse gas concentrations beyond the limit of ice coring in Antarctica, reconstructions have fo- cused on the past 60 Myr BP (Pagani et al., 1999, 2005; Pearson and Palmer, 2000; Royer et al., 2001). During this period, oxygen and carbon isotope records from benthic foraminifers indicate large climate fluctuations that coincide with perturbations of the carbon cycle (Zachos et al., 2001). (2) To quantify the potential of the ocean as a sink for $\mathrm{CO}_{2}$, carbonate chemistry reconstructions focus on benthic foraminifers (Marchitto et al., 2005; Sanyal et al., 1995; Yu and Elderfield, 2007). The glacial deep ocean is thought to be the largest carbon reservoir.

\section{Surface seawater carbonate chemistry}

As $\mathrm{CO}_{2}$ is well mixed in the atmosphere and is exchanged at the air-sea interface, knowledge of past sea surface carbonate chemistry can place constraints on past atmospheric $\mathrm{pCO}_{2}$. Boron isotopic compositions $\left(\delta^{11} \mathrm{~B}\right)$ in marine carbonates record past seawater $\mathrm{pH}$ (Hemming and Hanson, 1992; Hönisch et al., 2004; Reynaud et al., 2004; Sanyal et al., 1996, 2000, 2001). Laboratory and sediment validation studies have investigated vital shell size and dissolution effects on $\delta^{11} B$ of planktic foraminifers and corals. Symbiont photo- synthesis sequesters $\mathrm{CO}_{2}$ and thereby increases $\mathrm{pH}$ in the calcifying environment of foraminifers (Jørgensen et al., 1985; Rink et al., 1998) and corals (Al-Horani et al., 2003). Respiration has the opposite effect. In planktic foraminifers, these effects have significant consequences for the recorded pH (Hönisch et al., 2003). As symbiont-bearing foraminifers appear to grow larger under higher light levels (Spero and Lea, 1993), higher $\delta^{11} \mathrm{~B}$ of larger shells of the symbiont-bearing foraminifer Globigerinoides sacculifer is interpreted to reflect a shallower growth habitat (Hönisch and Hemming, 2004). The largest shells record surface seawater $\mathrm{pH}$, and because these shells are also the least susceptible to dissolution (typically resulting in offsets to lighter isotopic values), Hönisch and Hemming (2004) recommend using large shells for paleoreconstructions.

A 400-kyr record of $\delta^{11} \mathrm{~B}$ in large $G$. sacculifer shells from an open ocean sediment core in the equatorial Atlantic shows a 0.18 unit higher glacial ocean $\mathrm{pH}$ compared to interglacials (Hönisch and Hemming, 2005). This is consistent with previous results for Pacific and Atlantic surface seawater pH (Sanyal et al., 1995). Corresponding aqueous $\mathrm{PCO}_{2}$ estimations 